\title{
Utilização do Custeio ABC na Montagem de Sistema de Cobrança Interno para os Departamentos de TI: Um Estudo de Caso em um Banco de Varejo
}

Doutorado em Controladoria e Contabilidade pela Universidade de São Paulo - USP

Professor da Fundação Universidade Regional de Blumenal - FURB

Rua Antonio da Veiga, 140. Victor Konder. Blumenau/SC. CEP: 89012-900

E-mail: fbezerra@furb.br

Marines Lucia Boff

Mestrado em Ciências Contábeis pela Fundação Universidade Regional de Blumenau -

FURB

Rua Oiapoc, 211, Agostini. São Miguel D'Oeste/SC. CEP: 89900-000

E-mail:marinesboff@hotmail.com

Adriano Lourensi

Mestrando em Ciências Contábeis pela Fundação Universidade Regional de Blumenau,

FURB

Professor da Universidade de Passo Fundo - UPF

Campus I - KM 171 - BR 285, São José. Passo Fundo/RS. CEP: 99001-970

E-mail: louren.si@upf.br

\section{RESUMO}

A Tecnologia da Informação (TI) tornou-se um poderoso instrumento impulsionador de mudanças em diversos setores da economia, o que não é diferente para os Bancos. $O$ investimento intenso em novas tecnologias tem alterado a forma como os Bancos prestam seus serviços. Em função disso, os departamentos de TI nos Bancos passaram a ser de fundamental importância para se alcançar diversos objetivos estratégicos nestas organizações. O problema é que nem sempre os responsáveis pelo consumo dos recursos de TI são, efetivamente, conhecidos dentro destas companhias. É natural que haja a centralização da atividade de TI e, também, por causa disso, os custos acabem sendo "represados" apenas nos departamentos de TI, inviabilizando a identificação dos responsáveis pelo consumo. Este estudo teve como objetivo propor um modelo de sistema de cobrança interno para os departamentos de TI. Para tanto, realizou-se uma pesquisa exploratória em um único caso com tratamento qualitativo. Foi desenvolvido um modelo que utiliza o método de Custeio Baseado em Atividades para criação de uma "fatura gerencial" que segrega o consumo de recursos de TI em: plataforma alta e baixa, serviços específicos e o consumo com projetos em andamento fazendo com que os responsáveis pelo consumo sejam identificados.

Palavras-chave: Departamento de Tecnologia da Informação. Custeio baseado em Atividades. Sistema de Cobrança Interno. 


\title{
Use of $A B C$ in the assembly of Internal Chargeback System for the Departments of IT: A Case Study in a Retail Bank
}

\begin{abstract}
The Information Technology (IT) has become a powerful instrument that driver the changes in various sectors of the economy, this is no different to the banks. The intense investment in new technologies has changed the way that banks lend their services. As a result, the departments of IT in Banks have become of vital importance to achieve several strategic objectives in these organizations. The problem is not always the responsible for the consumption of IT resources is known within these companies. It is natural that there is the centralization of the activity of IT and also, because of this, the costs end up being "assigned" only to the IT departments. This study aimed to propose a model of internal system of charging for the departments of IT. For this, an exploratory research was made into a single case with quality treatment. It was developed a model that uses the method of Activity-Based costing for creation a "management bill" that make clear the consumption of resources in IT: high and low platform, services and consumption with specific projects in progress so that those responsible for consumption can be identified.
\end{abstract}

Key-words: Information Technology Departments. Activity-Based Costing. Internal Chargeback System.

\section{INTRODUÇÃO}

As áreas de Tecnologia de Informação (TI) nas organizações têm como objetivo a administração do processamento de sistemas corporativos centralizados por meio da aquisição e/ou desenvolvimento de tecnologias capazes de suportar esse processamento.

A evolução da TI e a evolução das instituições financeiras estão intrinsecamente relacionadas (Guilardi Filho, 1989). Sobre esse assunto, Lunardi, Maçada e Becker (2002, p.1) afirmam que 


\section{Utilização do Custeio ABC na Montagem de Sistema de Cobrança Interno para os Departamentos de TI: \\ Um Estudo de Caso em um Banco de Varejo}

Francisco Antonio Bezerra, Marines Lucia Boff, Adriano Lourensi

atualmente a área bancária é um dos setores que mais têm investido em Tecnologia de Informação (TI), tendo seus produtos e serviços fundamentalmente apoiados por essa tecnologia (Albertin, 1998). Para se ter uma idéia, o setor bancário brasileiro investiu, em 1999, cerca de R\$2,5 bilhões em equipamentos de informática e de comunicação e programas (Febraban, 2000). Com relação à América Latina, projeta-se um crescimento de 60\% nos investimentos de 1999 a 2003, totalizando investimentos em TI superiores a US\$ 40 bilhões (Lara; Perdómo e Jimenéz, 1999). O computador tem exercido um forte impacto sobre as operações dos bancos, sendo hoje, talvez, a indústria bancária a mais informatizada de todas (Drucker, 1999). Peters (1993), fazendo um retrospecto sobre o setor bancário, o apontou como o lugar mais evidente para se procurar as manifestações de TI do século XXI.

Conhecer os investimentos em $\mathrm{Tl}$ e o impacto que ela proporciona nos bancos é uma questão essencial para esse tipo de organização, que atua num ambiente extremamente competitivo, onde a atenção para o alinhamento dos negócios e das estratégias de informação deve ser o primeiro foco no esforço organizacional. A necessidade de que os executivos desse tipo de organização, tanto da área de tecnologia como dos demais setores que a utilizam no auxílio as suas atividades, saibam gerenciar e justificar os recursos empregados em TI é evidente.

Segundo a Febraban (2005), o número de transações bancárias suportadas pela utilização da TI teve aumentos superiores a 20\% de 2002 para 2003. Ainda, segundo a Febraban (2005), os investimentos totais dos bancos em TI têm aumentado no período de 2000 a 2003: 


\section{Utilização do Custeio ABC na Montagem de Sistema de Cobrança Interno para os Departamentos de TI: \\ Um Estudo de Caso em um Banco de Varejo \\ Francisco Antonio Bezerra, Marines Lucia Boff, Adriano Lourensi}

Os investimentos dos bancos em TI no ano de 2003 totalizaram 4,2 bilhões de reais, retratando um aumento de $19 \%$ em relação ao ano anterior. Se considerarmos que tradicionalmente os investimentos representam algo em torno de $35 \%$ do total gasto em $\mathrm{TI}$ pelos bancos, teríamos a impressionante cifra de 11,5 bilhões de reais direcionados à tecnologia pelas instituições financeiras. Quanto aos investimentos, cabe observar no ano passado [2003] a crescente tendência de terceirização dos serviços de desenvolvimento, com um incremento de $69 \%$, enquanto os serviços de desenvolvimento no próprio banco foram reduzidos em $42 \%$. O crescimento de $201 \%$ verificado nos equipamentos e linhas de comunicações pode ser explicado pela retração havida em 2002 e pela implementação das redes de correspondentes bancários.

A Tabela 1 demonstra a evolução dos investimentos dos bancos em $\mathrm{Tl}$ e apresenta um quadro da crescente importância desse tipo de investimento para os bancos.

Tabela 1 - Evolução dos Investimentos em TI nos Bancos

\begin{tabular}{lrrrrr}
\hline & \multicolumn{3}{c}{ Investimentos em R\$ milhões } & \multicolumn{2}{c}{ Variação } \\
\multicolumn{1}{c}{ Tipos } & 2000 & 2001 & 2002 & 2003 & $2002 / 2003$ \\
Hardware & 1.331 & 1.476 & 1.610 & 1.843 & $14,40 \%$ \\
Equipamentos/ linhas de comunicações & 431 & 301 & 193 & 581 & $201,40 \%$ \\
Softwares adquiridos de terceiros & 517 & 509 & 699 & 1.179 & $68,60 \%$ \\
Softwares desenvolvidos no próprio banco & 613 & 838 & 1.035 & 597 & $-42,30 \%$ \\
Total & $\mathbf{2 . 8 9 2}$ & $\mathbf{3 . 1 2 4}$ & $\mathbf{3 . 5 3 7}$ & $\mathbf{4 . 1 9 9}$ & $\mathbf{1 8 , 7 0 \%}$ \\
\hline
\end{tabular}

Fonte: Febraban (2005)

É indiscutível a importância da TI na indústria financeira. Existem diversas razões para a evolução da tecnologia nos bancos, dentre elas: redução de custos, criação de valor, inovação, redução de riscos, "virtualização" dos produtos e diferenciação do produto (Cohen, 2002).

Nolan (1979) dividiu a evolução da utilização da TI em diversas fases, que vão da Iniciação até a Maturidade. O aspecto da redução de custos é claramente percebido na 
fase de Iniciação. Os bancos aproveitaram a fase de utilização da TI para redução de custos, principalmente, para redução do número de funcionários que realizavam tarefas repetitivas de forma manual.

A disponibilização de serviços 24 horas, por intermédio de um caixa eletrônico ou internet, aumenta o valor percebido pelo cliente dos serviços oferecidos pelos bancos. Esse aumento de valor é transferido para a cobrança de tarifas específicas pela utilização desses canais de atendimento.

Alguns dos novos serviços criados pelos bancos somente puderam ser ofertados ao público pela utilização intensiva da TI. A Transmissão Eletrônica de Dados (TED) é um exemplo disso.

A necessidade de aumento da segurança das transações bancárias que ocorrem de forma descentralizada em todo território nacional, bem como a implementação de controles governamentais da circulação de dinheiro no mercado, são razões que motivam a criação de controles dos riscos operacionais nos bancos. Um exemplo disso é o novo SPB (Sistema de Pagamento Brasileiro), desenvolvido com o intuito de diminuir o risco sistêmico do mercado financeiro brasileiro. A indústria financeira, após um grande período inflacionário, precisou encontrar novas fontes de recursos que pudessem substituir os recursos provenientes dos lucros inflacionários (Bezerra, 2000). Uma das formas encontradas foi a incorporação de novos locais nos quais são feitas transações. A diferenciação do produto é algo fundamental na prestação de um serviço financeiro. A customização do serviço de acordo com as necessidades de um cliente é uma realidade na indústria financeira já há algum tempo. Departamentos de "Operações Estruturadas" estão sendo criados para simular operações financeiras complexas que envolvem diversos produtos em um único serviço. A fidelização dos clientes passa pela capacidade que os bancos possuem de se adaptar à estas novas necessidades, cada vez mais complexas. A integração entre os sistemas operacionais, o desenvolvimento de sistemas especialistas em análise de crédito, equipamentos eletrônicos que disponibilizam diversos produtos financeiros, integração das operações realizadas em correspondentes bancários 
com as demais operações realizadas em outros canais de distribuição dos produtos, são alguns exemplos de como os bancos se preparam para diferenciar seus produtos em relação aos demais do mercado.

Contudo, o aumento da importância dos custos de TI não vem necessariamente acompanhado pela identificação dos departamentos responsáveis pelo consumo de tais recursos. A regra geral é de centralização destes recursos em departamentos especialistas responsáveis pela gestão de contratos ou de operacionalização das redes e equipamentos que compõem a estrutura de TI nos Bancos.

Nesse contexto, surge a seguinte questão-problema deste estudo: Quais os requisitos para o desenvolvimento de um sistema de cobrança interno para departamentos de TI e como a metodologia de custeio $A B C$ se ajusta a essas necessidades?

Assim, este estudo tem como objetivo propor um modelo de sistema de cobrança interno para os departamentos de TI em bancos. Para tal, realizou-se um estudo exploratório na área de $\mathrm{TI}$

de um banco de varejo, caracterizado por um estudo de caso. Utilizou-se o tratamento qualitativo visto que buscou-se conhecer as características do setor de $\mathrm{TI}$.

Este trabalho está estruturado em seis seções. Na sequência desta primeira seção apresenta- se o método de pesquisa utilizado no estudo. Na terceira seção abordam-se as condições necessárias para o uso de um sistema de cobrança interno. Depois disso, explana-se a descrição geral do modelo de sistema de alocação de custos proposto e principais definições utilizadas. Por último, apresentam-se as referências utilizadas para dar embasamento teórico ao estudo.

\section{METODOLOGIA}

Para Rudio (1993, p.9), "a fim de merecer o qualitativo de científica, a pesquisa deve ser feita de modo sistematizado utilizando, para isto, método próprio e técnicas 
específicas e procurando um conhecimento que se refira à realidade empírica. " Realidade empírica para o autor é "tudo que existe e pode ser conhecido através da experiência".

Neste estudo, a busca das respostas à questão-problema deu-se, fundamentalmente, por meio de pesquisa exploratória. Conforme Raupp e Beuren (2004, p. 80), utiliza-se esse tipo de pesquisa quando "busca-se conhecer com maior profundidade o assunto, de modo a torná-lo mais claro ou construir questões importantes para a condução da pesquisa".

A pesquisa baseou-se num estudo de caso. Gil (2002, p.73) salienta que "o estudo de caso é caracterizado pelo estudo profundo e exaustivo de um ou de poucos objetos, de maneira a permitir conhecimentos amplos e detalhados do mesmo". A abordagem da pesquisa é de natureza qualitativa. Cortes (2002, p.237) cita que este tipo de pesquisa "possibilita descrever as qualidades de determinados fenômenos ou objetos de estudo".

\subsection{Critérios de Alocação de Custos das Áreas de TI}

Antes da definição e escolha dos critérios para alocação dos custos de $\mathrm{Tl}$, é importante definir como esses departamentos podem ser considerados dentro da estrutura organizacional. Existem três estruturas básicas para os departamentos de TI: Departamento de Suporte; Departamento de Serviço e Centro de Resultado.

Considerar o departamento de TI como Departamento de Suporte é assumir que este presta um serviço comum a todos os produtos e departamentos da companhia. Dessa forma, o departamento de TI tem seu próprio orçamento, que é somado aos demais recursos considerados como overhead da empresa. Nesse caso, os usuários dos serviços de TI não são cobrados pelo consumo de serviços internos.

Para Shaller (1974, p. 41), considerar o departamento de TI como departamento de suporte tem algumas vantagens:

a) Incentiva o desenvolvimento de novas aplicações (sistemas), já que os usuários 
não serão cobrados pelas experiências que fizerem com seus aplicativos;

b) Essa estrutura é simples e nenhuma informação adicional é necessária para implementá-la.

As desvantagens são:

a) O departamento de $\mathrm{Tl}$ é visto como um departamento que adiciona apenas custos para a produção, sem nenhuma contrapartida para a companhia;

b) O orçamento é a única ferramenta disponível para controlar os gastos dos departamentos de TI; e

c) Pelo fato de não serem cobrados, os usuários tendem a consumir os recursos de TI de forma exagerada.

Por outro lado, considerar o departamento de TI como Departamento de Serviço significa considerar que qualquer departamento que fizer uso dos serviços prestados pela TI deverá pagar por eles. Os benefícios desse tipo de estrutura são (Shaller, 1974):

a) Os departamentos usuários ao serem cobrados pela utilização somente farão solicitações cujos benefícios excedam o custo da prestação de serviço;

b) A cobrança pelo serviço interno leva a uma consequente avaliação do serviço que está sendo prestado pelo departamento de TI.

No entanto, existem desvantagens na cobrança dos serviços internos de TI:

a) A empresa incorre em custos para criação e monitoramento dos controles de consumo por departamento;

b) Departamentos com orçamentos pequenos e com forte utilização de TI vêem-se limitados quanto ao desenvolvimento de novos sistemas; $\mathrm{e}$

c) Os mecanismos de cobrança nem sempre são entendidos pelos usuários e 


\section{Utilização do Custeio ABC na Montagem de Sistema de Cobrança Interno para os Departamentos de TI:}

Um Estudo de Caso em um Banco de Varejo

Francisco Antonio Bezerra, Marines Lucia Boff, Adriano Lourensi

acabam gerando desconfiança quanto ao custeio e descontentamento interno pela cobrança.

A terceira forma de se entender o departamento de TI é como Centro de Resultado. Nesse caso, os usuários são cobrados por meio de taxas de mercado (ou preços internos), como se o departamento de TI fosse um bureau de serviços de TI. Essa forma de enxergar o departamento de TI facilita a avaliação de desempenho do departamento e a comparação com empresas externas que prestam os mesmos serviços.

No entanto, os serviços internos prestados pelo departamento de TI nem sempre possuem preço definido pelo mercado (Drury, 2000). Além do mais, tal forma de encarar esse departamento pressupõe uma forte autonomia dos demais departamentos da empresa, que poderão optar por serviços prestados por empresas externas, caso elas cobrem preços inferiores às taxas cobradas internamente.

Embora seja considerada superior em relação ao Centro de Custos, pesquisas indicam que a estrutura de Centros de Resultado é pouco utilizada pelas empresas nos Estados Unidos e no Japão. Sobre esse assunto, Sakurai (1997, p. 222) esclarece que

a principal razão que as empresas japonesas têm para não usar o método do centro de lucro é que as informações internas são altamente confidenciais. Como a habilidade de o administrador buscar sempre o custo mais baixo está implícita no método do centro de lucro, a empresa precisa estar disposta a mostrar suas informações para terceiros. Se a empresa não aceita isso, deve- se utilizar o método do centro de custo.

O autor afirma que os custos de "processamento de dados" podem ser tratados ou como "o erhe d" ou podem ser "apropriados ou transferidos a outros departamentos". 
O departamento de processamento de dados pode ser considerado como sendo parte da matriz da empresa ou parte da fábrica. Se tratado como parte da fábrica, seus custos são considerados como $o$ erhe $d$ da fábrica. Estes custos não são apropriados ou transferidos a departamentos de operação, para fins de orçamento (Sakurai, 1997, p.222).

O autor segue apresentando uma série de pesquisas realizadas nos Estados Unidos e no Japão, cujos resultados indicam que grande parte das empresas já utiliza critérios para alocação dos custos dos departamentos de TI. "[...] Segundo uma pesquisa efetuada nos Estados Unidos por Freeman e Liao, em 1981, 89\% das empresas apropriam os custos do departamento de processamento de dados para avaliação de desempenho. [...] o resultado no Japão foi de 75\% [...]".

Existem diversos trabalhos que concluem sobre os benefícios que se pode atingir com a alocação dos custos dos departamentos de TI, ou em outras palavras, com a necessidade de criação de Sistemas de Cobrança Internos para os departamentos de TI (Drury, 2000; Nolan, 1977; Nolan, 1979; Finney, 1981; Doost, 1997; Davies, 1989; Cushing, 1976; Shaller, 1974; Bisgay, 1987; Gauntt; Porter, 1985 e Flower, 1988).

Essa crescente preocupação com a alocação dos custos dos departamentos de TI tem cinco razões principais (Drury, 2000):

a) Os gestores têm buscado controlar o crescimento rápido das despesas com $\mathrm{TI}$. Apesar dos custos com equipamento e soft re estarem em queda, os custos com operação e manutenção tendem a aumentar;

b) Os custos de suporte nos departamentos de $\mathrm{TI}$ mostram mudança de comportamento. Esses departamentos vão continuar funcionando como árbitros na avaliação de novas solicitações de equipamentos e/ou de aplicativos dos demais departamentos da empresa. Todavia, cresce a ideia de que os demais departamentos (e não a TI) devem arcar com todas as despesas de tecnologia por eles consumidas: sua rede interna, equipamentos, soft res etc. Para 0 
departamento de $\mathrm{TI}$ sobrariam os custos de desenvolvimento, de processamento centralizado e de operacionalização e apoio à rede;

c) A necessidade de determinação de custos mais precisos nas organizações vem crescendo (Johson e Kaplan, 1996);

d) No passado, a TI era utilizada para coleta de dados e processamento de transações. Atualmente, afeta toda a organização: estrutura, processo de gerenciamento, recursos humanos (Silva, 2001) e, inclusive, o relacionamento com os clientes (exemplos disso são os próprios bancos). O gerenciamento dos recursos e a eficiência dos investimentos em TI tornaram-se fundamentais para as organizações; e tipo de empresa teria benefício com a implementação de sistemas de cobrança internos para TI.

Os Bancos, foco de análise deste estudo, encaixam-se perfeitamente nessa descrição: apresentam uma grande concentração de suas despesas em itens relacionados à TI. Além disso, existe uma descentralização significativa por toda a empresa, já que a utilização dos recursos oferecidos pela TI está disseminada por toda a organização (Febraban, 2005).

\subsection{Avaliação de Alternativas para o Sistema de Cobrança Interno}

As alternativas para os sistemas de cobrança internos podem ser segregadas em alternativas de bases de alocação de custos e alternativas de métodos de alocação dos custos dos departamentos de TI. As bases de alocação dos custos são divididas em duas categorias: método do fator único e método dos fatores múltiplos. Já os métodos de alocação se dividem em alocação total ou parcial dos custos.

Segundo Sakurai (1997, p. 227), o método do fator único aloca os custos aos usuários por intermédio de apenas um fator de apropriação. Isso é viável em situações cujas dimensões do departamento de TI não sejam significativas em relação às despesas totais da empresa. Ademais, esse departamento deve executar sempre as mesmas tarefas de processamento de forma muito similar (padronizada) para todos os seus 
usuários. Nesse caso, a empresa deve buscar um fator de alocação que seja um substituto razoável para ser definido como direcionador do custo total de TI. Por exemplo, se as despesas de pessoal são as mais significativas do departamento, talvez a hora de mão-de-obra direta seja um bom direcionador para servir de critério de alocação para as demais despesas da área de TI. Se, por acaso, a principal despesa for, na verdade, a depreciação dos equipamentos, a opção pelo direcionador único para as despesas de $\mathrm{TI}$ pode ser o tempo de CPU (Centr Processing nit).

Sakurai (1997, p. 227) adverte para o fato de que a alocação por fator único atrai pela simplicidade do critério. Contudo, caso a base de alocação não seja adequada para a distribuição dos custos entre os usuários, isso acarretará uma série de conflitos entre estes e o departamento de TI.

Cushing (1976, p. 49) define a base de alocação de um único fator como sendo "uma única medida que reflete todo o conjunto de componentes disponíveis para os usuários durante a execução do aplicativo". O autor esclarece que a opção pela utilização de um mecanismo único para determinar o preço de transferência para os usuários é viável, caso haja uma uniformidade de tipos de equipamentos e de serviços prestados entre os usuários. Desse modo, a base única é facilmente entendida e aceita pelos usuários do serviço. Caso haja diferenciação entre equipamentos do sistema de processamento e os serviços sejam diferenciados também entre os usuários, a utilização de taxas únicas de alocação de custos não será facilmente entendida ou aceita pelos usuários.

A outra forma de alocação de custos é pelo método de critérios múltiplos. Este método é utilizado em situações nas quais a complexidade do sistema de processamento de dados não permite a adoção de um único direcionador para alocação dos custos aos usuários. Cushing (1976, p. 49) afirma que o método de critérios múltiplos caracteriza-se pela utilização de diversas taxas de alocação de custos para cada componente (ou grupo de componentes) disponíveis para os usuários na prestação de serviço. Isso significa que, como um aplicativo (soft re), ao ser processado pelo departamento de TI, consome 
recursos distintos (tempo de CPU, espaço em disco, linhas impressas, número de portas, transações de entrada e saída etc.), cada recurso (ou grupo deles) terá sua taxa específica de apropriação aos usuários de acordo com um critério que melhor explique o seu consumo.

Esse mecanismo de apropriação dos custos é mais justo nos casos em que existe uma diferenciação significativa de consumo de recursos entre os usuários dos serviços do departamento de TI. Embora seja mais justo, é também muito mais complicado e caro de ser desenvolvido e implementado. Além disso, sua complexidade pode não ser entendida pelos usuários dos serviços de TI.

Shaller (1974, p. 46) afirma que o método de critérios múltiplos "encoraja os usuários a empregar uma combinação de recursos que minimizaria o custo total do sistema". Porém, afirma que o sistema é complexo: "Infelizmente, o custo do coletor de dados e do gravador de registros é relativamente alto e se os usuários não entenderem a fórmula de determinação do preço, a vantagem do controle fica perdida" [grifo dos autores].

Com relação aos métodos de alocação de custos, os sistemas de cobrança internos podem ser parametrizados para alocação total ou parcial dos custos, e podem estar baseados em valores orçados ou em valores reais. A alocação de custos aos departamentos usuários pode ainda ser realizada por meio de uma taxa de apropriação fixa multiplicada pelo nível de consumo ou uma taxa que varia de acordo com horários de pico de utilização (preços de transferência flexíveis). As alocações de custos também podem ser realizadas por meio da utilização do Custeio Baseado em Atividades (Brewer, 1998). Essas são algumas das alternativas possíveis para um sistema de cobrança interno para os departamentos de TI.

Com relação ao método de alocação de custos totais, Sakurai (1997, p. 228) explica que "a meta do princípio de repasse total é eliminar todos os custos do departamento de processamento de dados; isto é, transferir todos os custos aos departamentos usuários dos serviços". 
Bisgay (1987, p. 57) menciona que "o custeio por absorção aloca todo o custo do sistema de informação aos usuários. Todavia, este método pode desencorajar o uso dos serviços do sistema de informação se as taxas forem altas que já é resultado de uma baixa utilização dos serviços".

No entanto, Cushing (1976) observa que existe a vantagem da simplicidade por trás da utilização do custeio por absorção, o que facilita também a sua compreensão por parte dos usuários (o autor não comenta sobre a aceitação). As desvantagens apontadas pelo autor são as mesmas apontadas pelos demais autores: variação dos valores das taxas de acordo com o nível de consumo; quando a taxa está alta, desencoraja a utilização do serviço; quando a taxa está baixa, encoraja a utilização, o que pode levar a problemas de insuficiência na capacidade de processamento.

$\mathrm{Na}$ alocação parcial dos custos, o sistema de cobrança interno é parametrizado para alocar apenas uma parte do custo para os usuários da prestação de serviços. A idéia central é que nenhuma ineficiência na prestação de serviço deve ser repassada aos usuários. De acordo com Sakurai (1997, p.228), "o princípio [do repasse parcial de custos] fundamenta-se na lógica de que somente custos diretos devem ser repassados, e os custos indiretos devem ser suportados pelo departamento de processamento de dados". Em outras palavras, aloca-se aos usuários apenas o que pode ser identificado como específico daquele usuário. Os custos estruturais (fixos) são assumidos pelo departamento de TI.

A opção descrita por Sakurai (1997) não é muito interessante. Bisgay (1987, p. 57) comenta que a alocação de custos inferiores ao custo total encoraja a utilização da capacidade instalada do sistema de informação. O autor ainda afirma que esse tipo de alocação de custos encaixa-se muito bem para as fases iniciais de implementação dos sistemas de cobrança internos. Além disso, o aumento dos custos compartilhados de processamento de dados inviabilizaria qualquer tipo de sistema de cobrança interno de $\mathrm{TI}$ se os custos indiretos não pudessem ser cobrados dos usuários.

O modelo descrito neste artigo mostra-se como uma alternativa diferente para 
alocação de custos diretos e indiretos para os usuários dos serviços de TI. O modelo contempla as características existentes no método de custeio $A B C$ : com múltiplos direcionadores e alocação parcial dos custos. Apenas os custos consumidos pelos usuários são alocados aos usuários. O custo da capacidade não utilizada permanece no departamento de TI.

\subsection{Avaliação da Eficiência do Sistema de Cobrança Interno}

A avaliação da eficiência do sistema de cobrança tem relação com a análise dos benefícios atribuídos e, efetivamente, obtidos pela implementação de um sistema de cobrança interno para os departamentos de TI. O trabalho de Nolan (1977) foi o primeiro que avaliou as consequências comportamentais e organizacionais da implementação de sistemas de cobrança internos para os departamentos de TI. Nolan (1977, p. 120) determinou quatro critérios para definir a utilidade do sistema de cobrança interno: compreensibilidade, controlabilidade, acco nt $i$ ity e incidência do custo/benefício.

Para Drury (2000, p. 302), a intenção de alterar o comportamento dos usuários e aumentar o controle sobre os custos com a utilização dos sistemas de cobrança internos faz com que esses sistemas devam incorporar características como: justiça, equanimidade, responsabilidade e controle.

Herman (1997, p. 24) também descreve os objetivos de um sistema de cobrança interno para TI. Segundo o autor, esses sistemas devem perseguir os seguintes objetivos: justiça, controle, simplicidade, encorajar eficiência, limitar o uso de recursos escassos e encorajar comportamentos importantes para a companhia.

Enfim, os autores são unânimes em afirmar que os sistemas de cobrança internos para $\mathrm{TI}$ devem possuir características que permitam ou facilitem sua implementação como instrumento de controle e de condução dos comportamentos considerados adequados para a empresa atingir seus objetivos. 
O modelo apresentado na próxima sessão descreve as fases e os principais atributos de um sistema de cobrança interno de $\mathrm{TI}$ baseado na metodologia de custeio $A B C$. Este modelo foi desenvolvido para um grande Banco de varejo. Os valores, bem como as informações sobre as áreas do departamento de TI foram alterados por questão de confidencialidade da informação. Contudo, o modelo se mostra como uma alternativa para modelagem de sistemas de cobrança interno de TI, pois apresenta um nível de detalhamento da informação que pode facilitar o entendimento por parte dos usuários internos e carrega características como compreensibilidade, controlabilidade, justiça (assumindo que a quantidade consumida seja uma proxy para justiça na alocação de custos).

\section{DESCRIÇÃO GERAL DO MODELO E PRINCIPAIS DEFINIÇÕES UTILIZADAS}

Nesta seção é descrita uma sequência de etapas, conforme evidencia a Figura 1, que vão desde o registro das despesas até o cálculo do custo da prestação de serviço e finaliza com a descrição da saída (chamada neste artigo de "fatura gerencial") que se espera do sistema de custeio. A análise do aplicativo de custeio utilizado pelo Banco não fez parte do escopo deste artigo. O aplicativo de custeio é denominado neste estudo de SACPD - Sistema de Apuração de Custos de Processamento de Dados. 


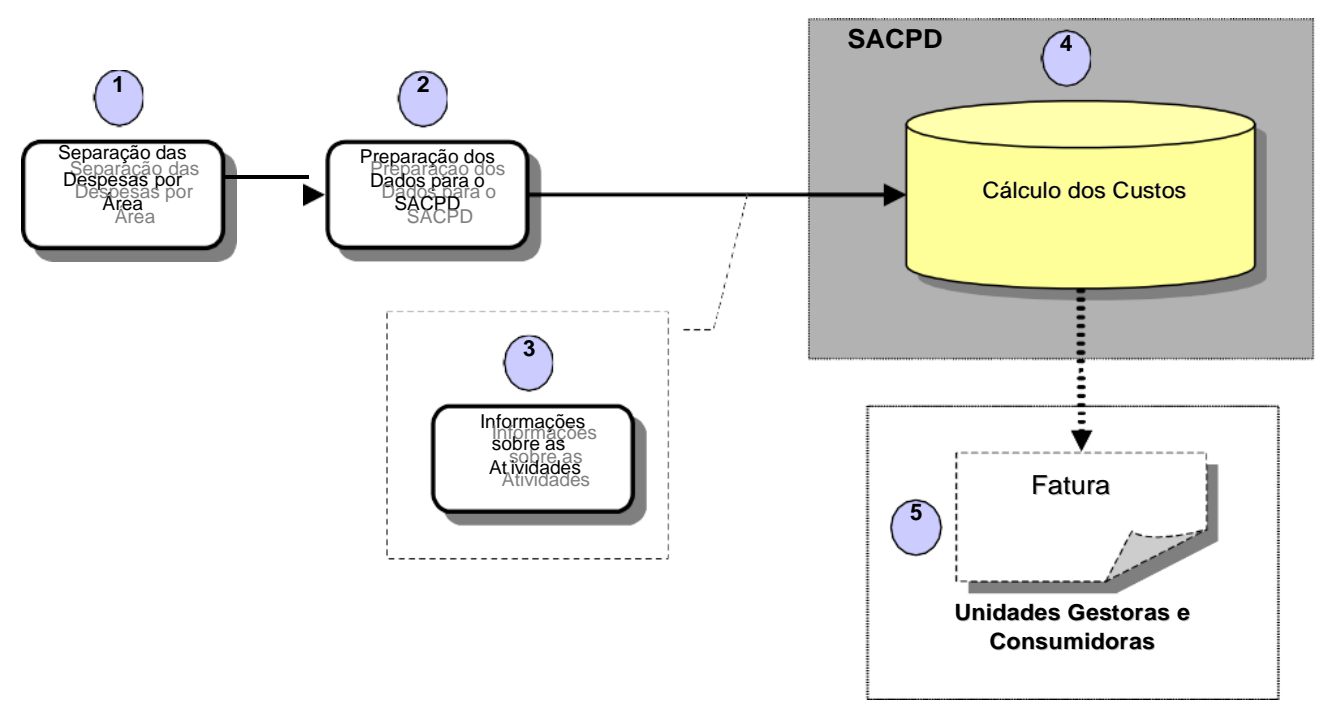

Figura 1- Etapas do Modelo Proposto

Fonte: os autores

O principal objetivo da proposição deste modelo é que o DPD possa se ressarcir dos recursos consumidos pela prestação de serviços internos e que os usuários de seus serviços possam se aperceber do quanto consomem de recursos que são gerenciados pelo DPD.

As informações coletadas em entrevistas nas diversas áreas do DPD levaram à conclusão de que o DPD executa uma gama de serviços que podem ser classificados de três formas distintas: Serviços de Plataforma Alta, Serviços de Plataforma Open ou Serviços Específicos.

Os serviços do DPD podem ser prestados no intuito de garantir o processamento de sistemas Mainframe e a infra-estrutura necessária a esta finalidade. Nestes casos, estes serviços são considerados como Serviços de Plataforma Alta e devem compor o custo dos aplicativos corporativos do Banco que utilizam a infra-estrutura disponibilizada pelo DPD. 
Outros serviços prestados pelo DPD são os Serviços de Plataforma Open que se constituem em um conjunto de atividades realizadas por algumas áreas do DPD para monitoramento e suporte à ambientes específicos de outros departamentos do Banco. Este serviço inclui tanto a instalação de soft res quanto a pesquisa de aplicativos, bem como a disponibilização de infra-estrutura básica para o pleno funcionamento destes ambientes. Os ambientes específicos interagem com o ambiente do DPD.

Outros serviços são os Serviços Específicos, os quais são prestados pelo DPD, exclusivamente, sob demanda de outras unidades do Banco como: instalação de antivírus, disponibilização de senha de acesso, criação de perfis de segurança, etc.

As macro-atividades de gerenciamento executadas pelas áreas administrativas do DPD, não são consideradas como serviços internos e são denominadas neste artigo como Atividades de Apoio. Também foram consideradas como Atividades de Apoio todas as atividades que são realizadas para dar suporte à execução dos Serviços de Plataforma Alta, Serviços de Plataforma Open e Serviços Específicos.

\subsection{Proposta para o Tratamento Adequado do DPD como Centro de Resultado}

As etapas necessárias para implementação do Sistema de Cobrança Interno dos Serviços de TI foram as seguintes: Separação do Consumo de Recursos por Área, Cálculo do Custo das Atividades, Associação dos Custos das Atividades e Custos Diretos aos Serviços Internos.

a) Separação do Consumo de Recursos por Área

O DPD precisou implementar os critérios de distribuição dos custos entre as suas áreas para que o sistema de custeio pudesse calcular os custos das atividades e por consequência dos Serviços Internos do DPD. Atualmente, as despesas são separadas de forma parcial e existem critérios que definem uma única área como sendo "por definição" onde a despesa deve ficar. Isto prejudicava o cálculo do custo dos serviços internos. 
b) Cálculo do Custo das Atividades

O SACPD deve estar apto para receber as informações de despesas e dos direcionadores que relacionam estas despesas com as atividades executadas pelas áreas do DPD. As atividades é que possuem o relacionamento com os serviços internos do DPD.

Após o cálculo do custo das atividades e do relacionamento dessas com os serviços internos, os serviços internos foram relacionados (por direcionadores específicos) e alocados para:

- Os aplicativos do Banco;

- As outras unidades do Banco (Serviços Específicos); ou

- Um elemento de custo sistêmico (do SACPD) que apenas acumula custo (nos casos de projetos em andamento).

A Figura 2 apresenta um detalhamento do fluxo pretendido para o DPD no cálculo de suas atividades: 


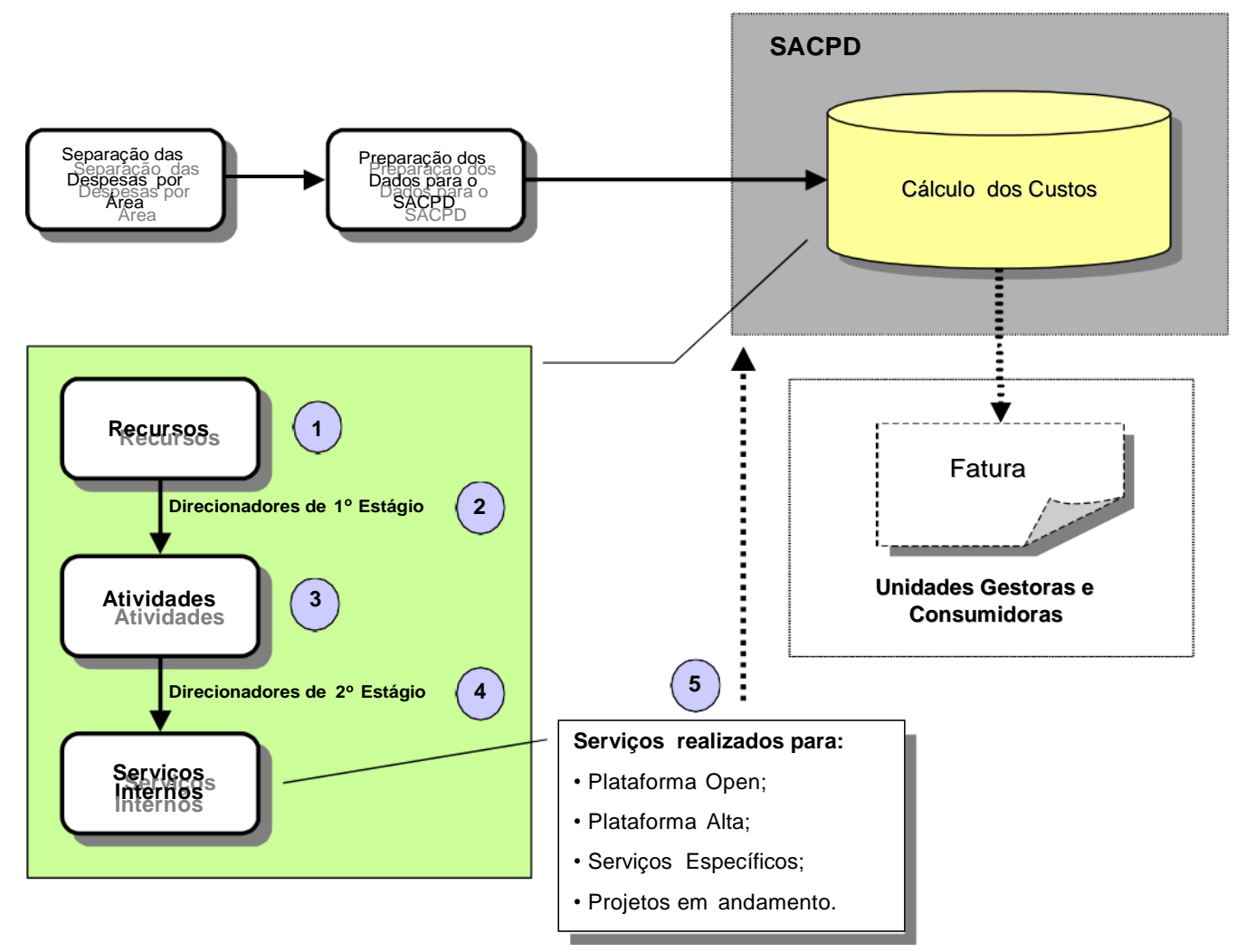

Figura 2 - Fluxo do Custeio das Atividades do DPD Fonte: os autores

Descrição das etapas:

1. As informações sobre os recursos (despesas) segregados por área do DPD são enviadas para o SACPD para que sejam relacionadas às atividades. O principal controle no modelo passa a ser o consumo de recursos na execução de uma atividade.

2. A criação de direcionadores de custeio de primeiro estágio (apontamento de horas, cronometragem, controle de número de execuções ou mesmo percentual do tempo de dedicação na execução de cada atividade) permitirá a associação desses recursos com as atividades. 
3. O custo da execução das atividades permitirá que se crie uma nova forma de se gerenciar recursos no DPD. Atualmente, observa-se quanto dos recursos estão sendo consumidos em cada uma das áreas. Depois de implantado o ABC, o DPD poderá avaliar como os recursos são consumidos pelas áreas do DPD. Esta informação deverá ser disponibilizada pelo SACPD.

2. As atividades serão agrupadas em diversos serviços prestados pelo DPD (destinado ao suporte à Plataforma Open, Plataforma Alta, Serviços Específicos ou mesmo registro da participação em projetos).

3. O SACPD deve, por sua vez, possuir critérios de alocação dos custos dos serviços internos. O resultado desta alocação é uma "fatura" que detalha o que foi consumido e como foram calculados os custos dos serviços internos demandados pelos demais departamentos do Banco.

O Sistema de Custeio Baseado em Atividades no DPD, foi estruturado de acordo com o que demonstra a Figura 3 abaixo: 
Etapa 1

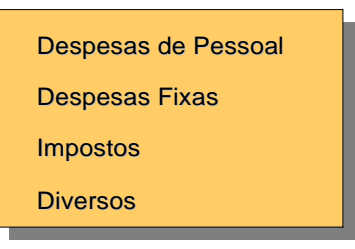

Etapa 2 - Custeio das Atividades

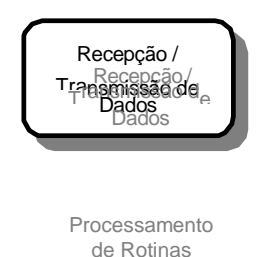

Levantamento de informações necessárias à associação dos custos às atividades do DPD (direcionadores de recursos).

Custeio das atividades ou relacionamento dos custos às atividades pelo tempo de execução das atividades.

a) Associação dos Custos das Atividades e Custos Diretos aos Serviços Internos

Para execução desta etapa, o SACPD possui métricas de consumo de máquina (mainframe) que serão utilizadas para alocação dos custos (de atividades e diretos de equipamentos) aos aplicativos do Banco. Verifica-se esta associação do custeio das atividades e dos serviços internos na Figura 4. 


\section{Utilização do Custeio ABC na Montagem de Sistema de Cobrança Interno para os Departamentos de TI:}

Um Estudo de Caso em um Banco de Varejo

Francisco Antonio Bezerra, Marines Lucia Boff, Adriano Lourensi

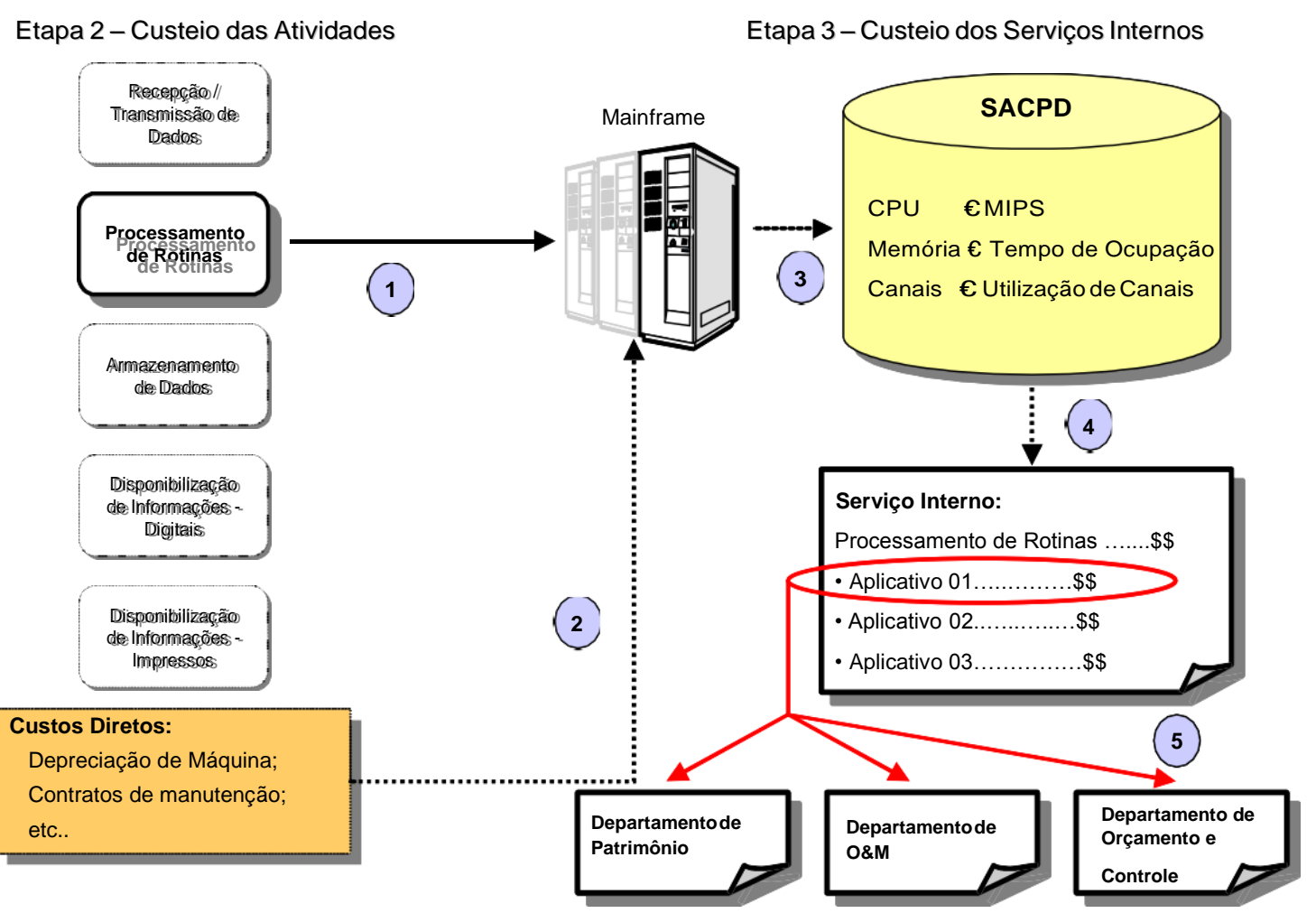


Figura 4 - Custeio dos Serviços Internos

Fonte: os autores

Descrição das etapas:

1. O SACPD deve permitir a associação dos custos de execução das atividades a um equipamento específico.

2. Os custos diretos dos equipamentos também serão associados pelo SACPD.

3. O total dos custos (de atividades e direto) será associado aos aplicativos do Banco por critérios de alocação de custos definidos no SACPD.

4. O SACPD deve permitir a visualização dos custos do Serviço Interno distribuído entre os aplicativos do Banco.

5. O SACPD deve disponibilizar tanto a visão consolidada (item anterior) como o consumo dos aplicativos distribuídos entre os usuários finais do aplicativo. Por conseguinte, será possível a visualização do custo da prestação de Serviço Interno por usuário.

Um Serviço Interno pode ser composto por diversas atividades, pode ter a participação de mais de uma área do DPD e esta decomposição precisa ser demonstrada pelo SACPD. Mesmo os Serviços Internos de caráter específico como os de Segurança Lógica (que não envolvem necessariamente consumo de máquina) ou do Suporte Técnico e Operação (Instalação de Soft re em Plataforma Open) devem ser cobrados dos demais departamentos do Banco sem onerar os aplicativos do Banco.

A forma como se desenha este modelo de custeio permite que o usuário final (o departamento que pagará pelo serviço) visualize como foi composto o custo que Ihe está sendo imputado.

$\mathrm{Na}$ Figura 5, analisa-se uma solicitação feita por um dos departamentos usuários sobre o seu consumo de recursos da área de TI. Caso seja solicitado a fazer explicações em relação ao custo dos serviços alocados aos demais 
departamentos do Banco, o DPD poderá extrair do SACPD; (1) as informações de consumo de máquina de determinado aplicativo; (2) quanto consumiu de custos diretos e de atividades; (3) quanto dos custos de atividade refere-se a Pessoal; (4) quais foram os critérios adotados para alocação destes custos ao aplicativo. Estas informações devem ser disponibilizadas pelo SACPD (5) aos Departamentos ou empresas ligadas, quando este for o caso.

Custos de Atividades

Pessoal;

Ocupação;

etc.

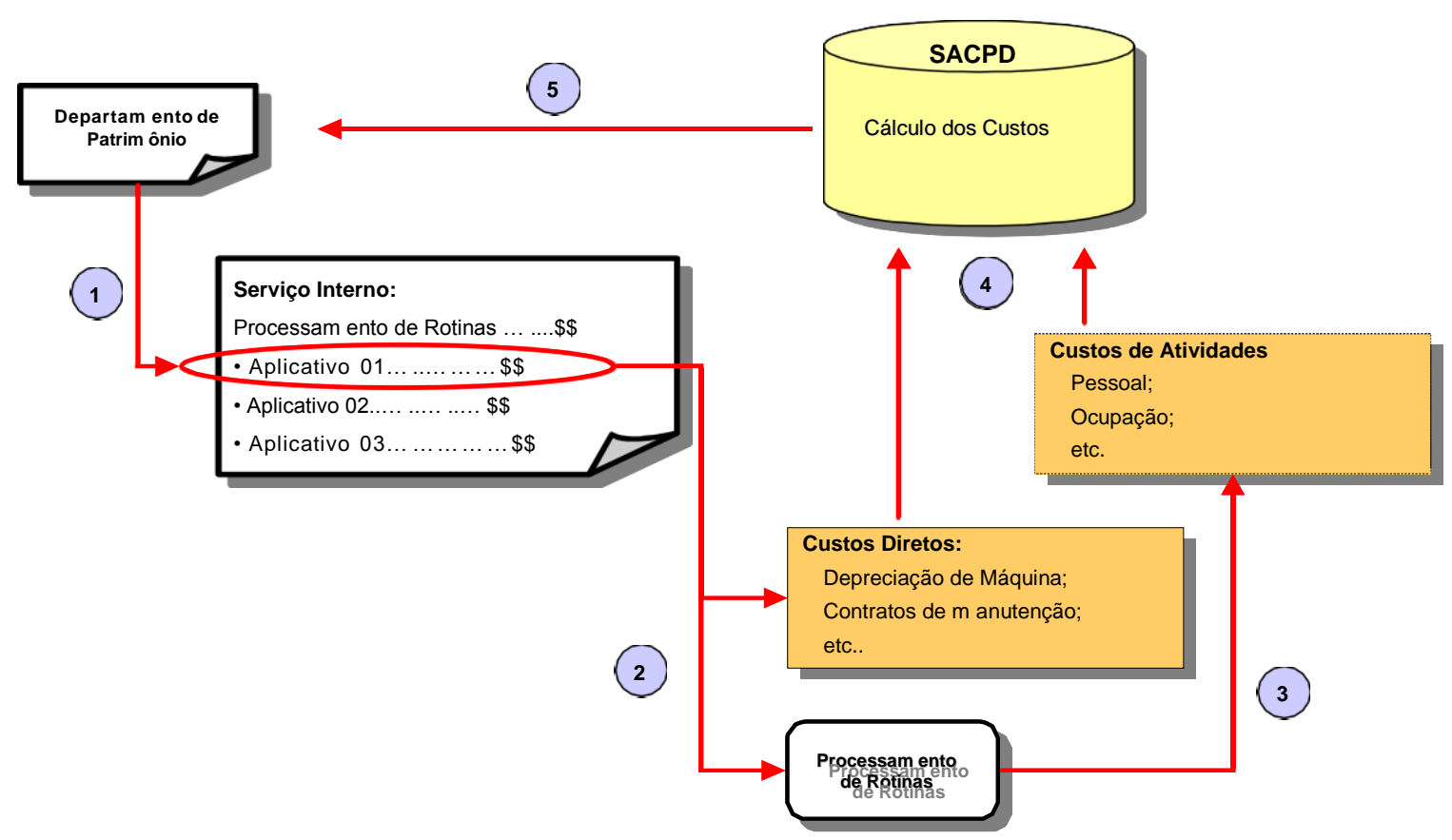

Figura 5 - Abertura dos Custos de Prestação de Serviço Fonte: os autores

Levando em consideração as diversas etapas de alocação de custos e os tipos de serviços prestados pelo DPD, é possível definir como deve ser estruturada a "fatura gerencial" a ser disponibilizada para os usuários finais. A Figura 6 apresenta um modelo da fatura gerencial dos serviços prestados pelo DPD:

A "fatura gerencial" apresenta todos os tipos de serviços prestados pelo DPD:

1. Plataforma Alta: apresenta a parcela dos custos de processamento das rotinas do 
Banco consumidas pelo departamento usuário.

2. Plataforma Open: representa a parcela dos custos consumidos pelo departamento usuário dos ambientes de Plataforma Baixa (Open) aos quais ele tenha relacionamento.

3. Serviços Específicos: custo da execução de serviços específicos para o departamento usuário por uma ou mais áreas do DPD. Este custo inclui também a parcela da amortização de custos de trabalhos finalizados (projetos) e já em fase de produção.

4. Trabalhos em Andamento: custos incorridos pelo DPD que ainda não serão ressarcidos pelos departamentos usuários. Refere-se à participação do DPD em projetos ainda não finalizados. Por isso, ainda não entram no somatório do valor da fatura a ser cobrado dos departamentos usuários.

Obviamente, os custos apresentados na "fatura" poderão ser abertos até o nível onde os usuários acharem necessário, de acordo com o que foi comentado anteriormente, uma vez que a composição destes custos pode ser extraída diretamente do SACPD. Desta forma, será possível separar a procedência dos custos na formação do preço de transferência, por exemplo. 


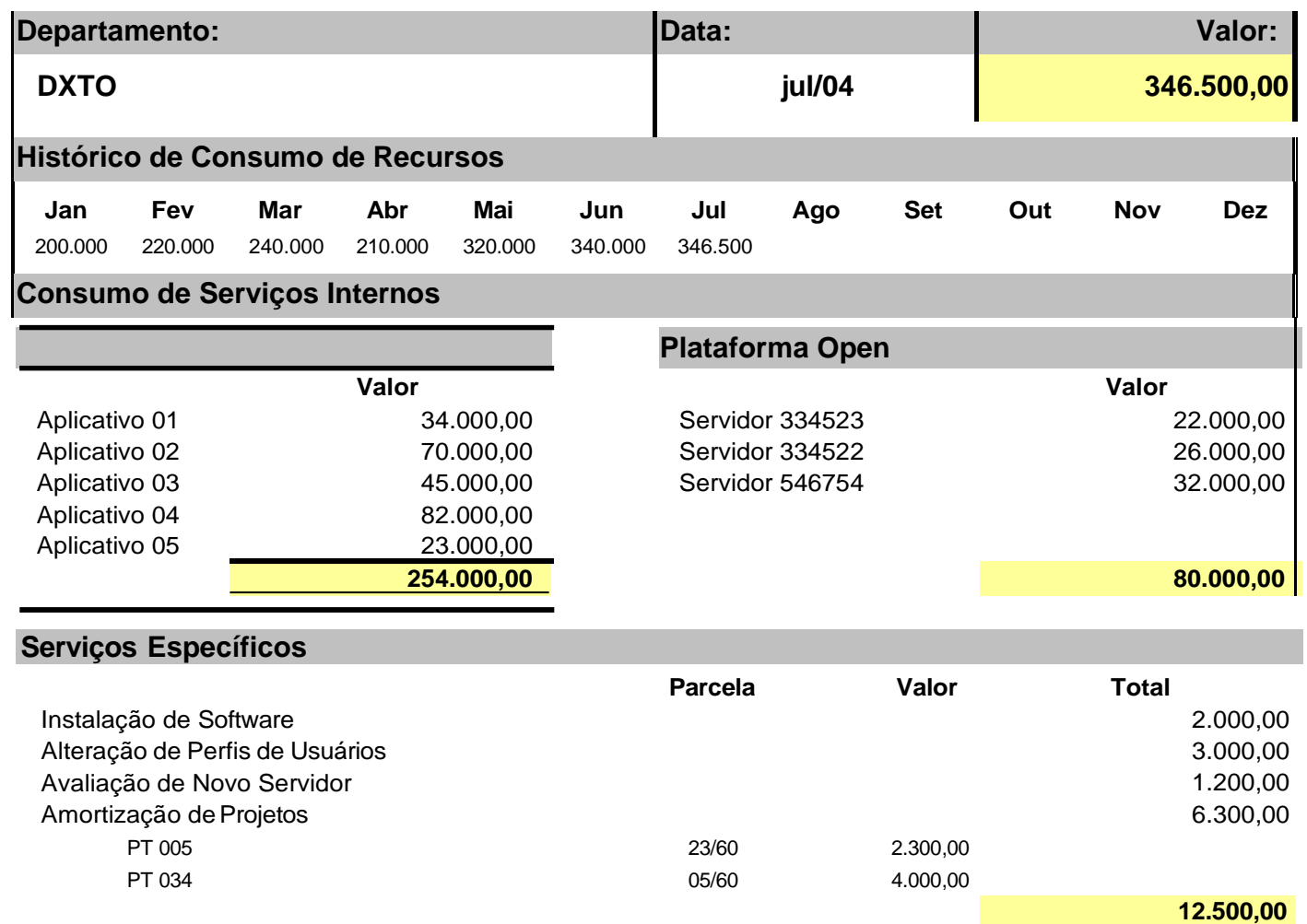

\section{Projetos em Andamento}

Desenvolvimento de Sistemas
MPTO
DRTP
Projetos
PT 005
PT 034

\begin{tabular}{ccc} 
Período/Mês & Valor & \multicolumn{1}{c}{ Total } \\
3 & $230.000,00$ & $660.000,00$ \\
7 & $430.000,00$ & \\
& & $456.000,00$ \\
6 & $320.000,00$ & \\
6 & $136.000,00$ &
\end{tabular}

$1.116 .000,00$ 


\section{CONCLUSÃO}

O modelo descrito neste artigo encaixa-se nas principais características de visualização de custos impostas aos sistemas de cobrança internos de TI. A alocação de custos aos usuários do serviço interno impõe, entre outros fatores: o controle de consumo de recursos por parte dos usuários; o controle de consumo de recursos por parte do prestador de serviço e a imputação de responsabilidade pelo consumo de recursos dentro da companhia dos serviços de suporte do DPD.

O Custeio Baseado em Atividades permite uma abertura da informação de custos que possibilita ao usuário um detalhamento considerável dos custos que estão sendo direcionados aos demais departamentos do Banco: sistemas (ou aplicativos) de cada departamento que são processados pelo DPD; serviços internos consumidos pelos aplicativos ou prestados de forma específica aos departamentos usuários; custo das atividades que compõem os serviços internos; recursos diretos que compõem os serviços internos; recursos que compõem as atividades (os recursos de pessoal, por exemplo, são alocados às atividades pelo tempo apontado para a atividade. Isto permite que o departamento usuário saiba inclusive o tempo do pessoal do DPD consumido na prestação do serviço e pode questionar esse tempo ou não).

A "fatura gerencial" criada neste modelo permite que os usuários tenham conhecimento da sua responsabilidade no consumo de recursos de $\mathrm{TI}$ segregados em plataforma alta e baixa, serviços específicos e também do consumo de recursos com projetos em andamento, que ainda não estão sendo cobrados do departamento usuário, mas já são informados para que os departamentos usuários tenham uma ideia da quantidade de recursos já consumidos. Outra utilização dada ao modelo de custo descrito neste artigo é como um mecanismo de associação dos custos de $\mathrm{Tl}$ aos produtos finais do Banco. Os departamentos usuários relacionam o consumo de recursos de $\mathrm{TI}$ às suas próprias atividades e se essas atividades estiverem relacionadas com um produto específico do Banco, tem-se o relacionamento do consumo de recursos de TI (área de 
Utilização do Custeio ABC na Montagem de Sistema de Cobrança Interno para os Departamentos de TI:

Um Estudo de Caso em um Banco de Varejo

Francisco Antonio Bezerra, Marines Lucia Boff, Adriano Lourensi

suporte) aos produtos finais do Banco.

\section{REFERÊNCIAS BIBLIOGRÁFICAS}

BEZERRA, F. A. Gestão Estratégica de Custos: Um Estudo de Caso sobre a Aplicabilidade do Método de Custeio ABC em Bancos. 2000, 198f. Dissertação (Mestrado em Controladoria e Contabilidade) Faculdade de Economia, Administração e Contabilidade, Universidade de São Paulo, São Paulo, 2000.

BISGAY, L. 1987. MAP Committee Issues SMA 4F: Allocation of Information Systems Costs. Management Accounting, 68(8):56-59.

BREWER, P.C. 1998. Developing a Data Center Chargeback System Using ABC. Journal of Cost Management. 12(3):41-47.

COHEN, M.F. 2002. Alguns Aspectos do uso da Informação na Economia da Informação. Ciência da Informação. 31(3):26-36.

CORTES, S.M. 2002. Vargas. Como fazer análise qualitativa de dados. In: BÊRNI, D.A. (coord.) Técnicas de pesquisa em economia. São Paulo, Saraiva, 408p.

CUSHING, B.E. 1976. Pricing Internal Computer Services: The basic Issues. Management Accounting. 57(10):47-50.

DAVIES, T.L. 1989. Use Chargeback Systems in the Allocation of Departments. South Dakota Business Review. 48(2):4-6.

DRURY, D.H. 2000. Assessment of Chargeback Systems in IT Management. INFOR, 38 (3): 293-313.

Federação Brasileira de Bancos - FEBRABAN. Disponível em http://www.febraban.com.br, acesso em 05/04/2005.

GIL, A.C. 2002. Como elaborar projetos de pesquisa. 4ª ed. São Paulo, Atlas, 175p.

GUILARDI FILHO, G. 1989. Custos de Sistemas e Processamento de Dados. São Paulo, SP. Dissertação de Mestrado. Escola de Administração de Empresas de São Paulo FGV/EAESP, FGV, $175 \mathrm{p}$.

HERMAN, J. 1997. Internal Chargeback: Keep it simple, but not to simple. Business 
Communication Review. 27 (4): 24-27.

JOHNSON, H.T. e KAPLAN, R.S.A. 1996. Relevância da Contabilidade de Custos. $2^{\underline{a}}$ ed. Rio de Janeiro, $239 \mathrm{p}$.

LUNARDI, G.L.; MAÇADA, A.C.G. e BECKER, J.L. 2002. O Impacto da Tecnologia de Informação (TI) nos Bancos Brasileiros, Americanos, Argentinos, Chilenos e Uruguaios. In: ENANPAD, 2002, Anais...Salvador. ENANPAD. 2002. CD-ROM.

NOLAN, R.L. 1977. Controlling the Costs of Data Services. HBR. Jul/Aug, p. 114-124.

RAUPP, F.M. e BEUREN, I.M. 2004. Metodologia da pesquisa aplicável às ciências sociais. In: BEUREN, I.M. (Org.). Como elaborar trabalhos monográficos em contabilidade: teoria e prática. 2. ed. São Paulo, Atlas, 200p.

RUDIO, F.V. 1993. Introdução ao projeto de pesquisa científica. Petrópolis, Vozes, $144 p$.

SAKURAI, M. 1997. Gerenciamento Integrado de Custos. São Paulo, Atlas, 279 p.

SHALLER, C. 1974. Survey of computer cost allocation techniques. Journal of Accountancy. 137(6):41-46.

SILVA, M.K. 2001. O Comprometimento com a Qualidade dos Sistemas de Informação: Um Enfoque nas Competências das Pessoas. Florianópolis, SC. Dissertação de Mestrado. Universidade Federal de Santa Catarina, Florianópolis, 121p.

Data de Submissão: 16/07/2008

Data de Aceite: 05/08/2008 